\title{
THE PECULIARITIES OF PARTICIPATION IN LEISURE ACTIVITIES PATIENTS WITH PHYSICAL DISABILITIES
}

\author{
Rūta Jonaitienè $(\mathrm{OT}) 1,2$, Aušra Adomavičienė $(\mathrm{PhD}) 1,2$ \\ 1 Department of Rehabilitation, Physical and Sports Medicine, Faculty of Medicine, \\ Vilnius University, \\ 2 Centre of Rehabilitation, Physical and Sports Medicine, Vilnius University Hospital
}

Introduction: Patients with physical disabilities doesn't engage leisure activity which previously provided pleasure but leisure activities with other patients at the hospital them are interested and it is important because it has a positive role in the psychoemotional status $^{1 / 2}$.

Purpose. To analyze leisure activities participation and find peculiarities patients with physical disabilities.

Method: The research was performed during inpatient rehabilitation program at the Center of Rehabilitation, Physical and Sports Medical during 2016-2017. In group leisure activities was attended 53 patients with physical disability: disability caused after stroke, head trauma, spinal cord injury, myelopathy. In research participated 30 men and 23 women, age mean was 59. Patients after the individual in-patient rehabilitation program were invited to participate 3 times a week during the afternoon in one hour's group leisure activities which were organized and held in the occupational therapy cabinet. Leisure activity every time was a new so each from 6 patients group who participated in the research was able to try 12 different leisure activities for 1 month.

Data collection methods: Activities Daily Living (ADL) test, Hospital Anxiety and Depression Rating (HAD) scale, Will questionnaire (VQ) and a direct, semi-structured interviews.

Results. At beginning majority patients often were hesitant $(p<0,01)$ and the end patients needed to relatively less support and encouragement to the participation in leisure activities $(p<0,01)$.
The research results reveal that anxiety and depression symptoms, significantly $(p>0,05)$ not declined. The analysis of patient participation creative and active leisure activities, there is a not statistically significant $(p>0,05)$ difference. Leisure activities the need reveals for key aspects: communication with others, spending time and others. It should be noted that the factors which reduce participation in group leisure activities are internal (76,8\%): self-doubt (29\%), fatigue (15,9\%), nervousness $(13 \%)$ and external $(23,2 \%$ ): the planned research $(12,4 \%)$, visit relatives $(6,2 \%)$, designated procedures $(4,6 \%)$.

Conclusions: Leisure activities can be used as a tool to improve the patients psychoemotional status and them to engage the afternoon in time at the rehabilitation section.

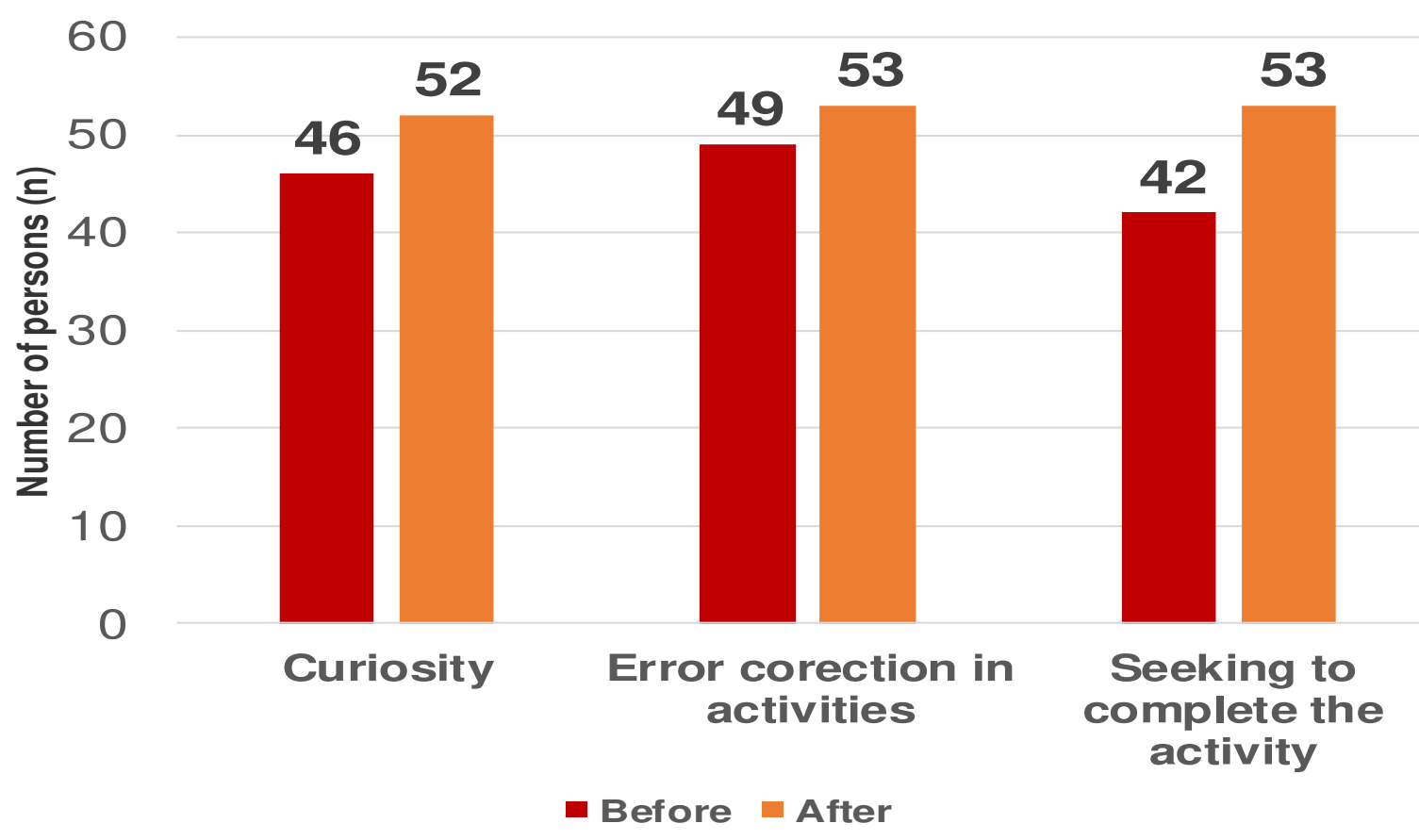

The positive motivation important parts change before and after the participation in leisure activities.

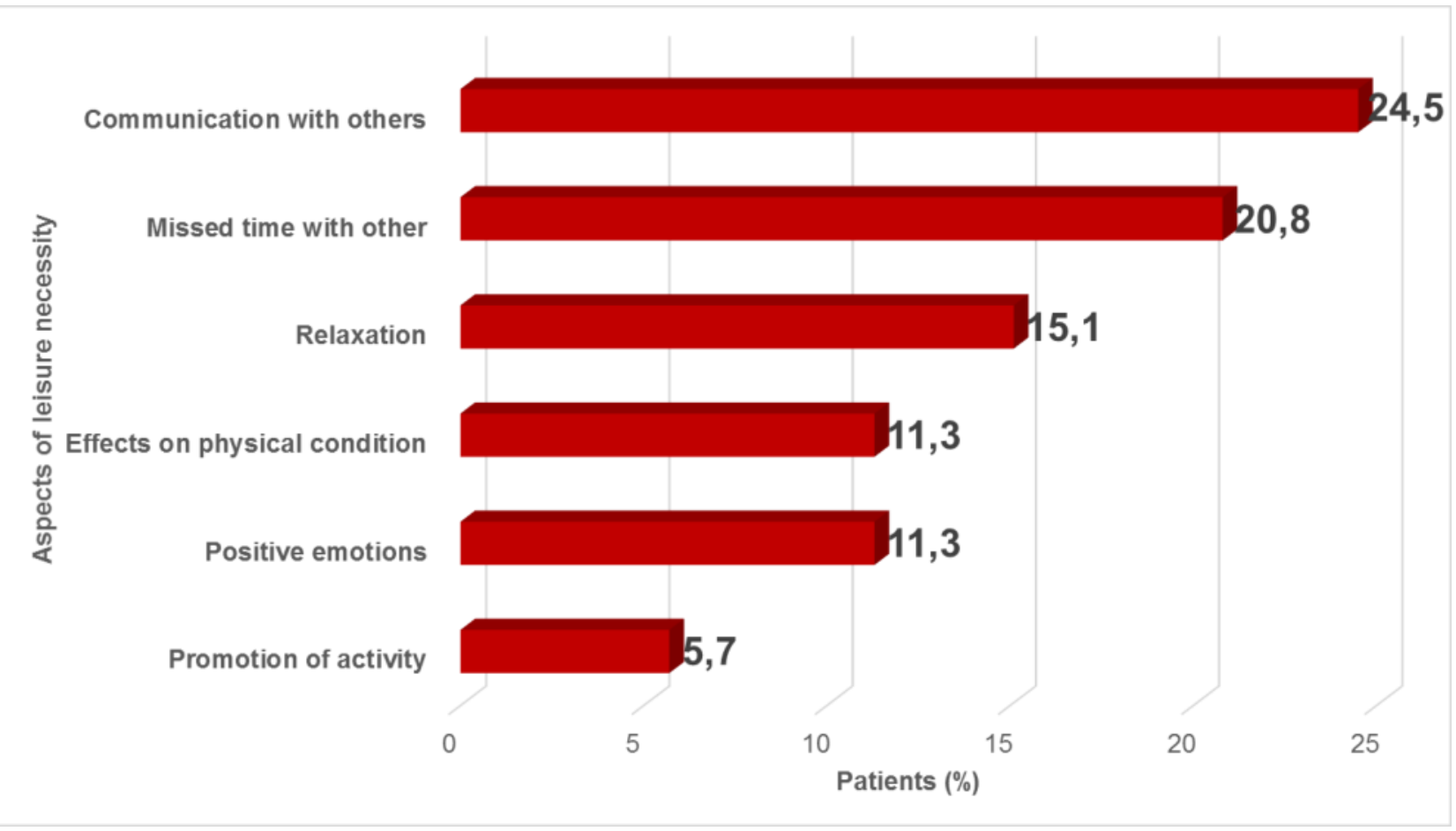

Necessity of leisure activities.

References: 1. CY Ch, Ching Man Wu, Chi Hung Yip, Ka Kin Yau. Getting through the day: exploring patients' leisure experiences in a private hospital Zenobia. Journal of Clinical Nursing. 2011;3257-3267.

2. Adams K. B, Leibbrandt S, Moon H. A critical review of the literature on social and leisure activity and wellbeing in later life. Ageing and Society. 2012; 31 (4): $683-712$. 